\title{
Armazenamento de sementes e aclimatização de Brassavola tuberculata Hook
}

\section{Seed storage and acclimatization of Brassavola tuberculata Hook}

\author{
Marichel Canazza de Macedo ${ }^{1}$; Derek Brito Chaim Jardim Rosa ${ }^{2}$; \\ Jackeline Schultz Soares ${ }^{3}$; Mariana Bento Tatara ${ }^{4}$; \\ Nilda Tiyoko Kobayashi Hofmmann ${ }^{4}$; Yara Brito Chaim Jardim Rosa ${ }^{5 *}$
}

\section{Resumo}

A semeadura in vitro e a aclimatização das plântulas produzidas são responsáveis pelo sucesso da produção de Orchidaceae. Este trabalho teve por objetivos 1) avaliar a viabilidade das sementes de $B$. tuberculata armazenadas em diferentes temperaturas e 2) avaliar o crescimento ex vitro de $B$. tuberculata em diferentes substratos. As sementes foram armazenadas, por 84 dias, sob três condições: temperatura ambiente $\left(23 \pm 2{ }^{\circ} \mathrm{C}\right)$, refrigerador $\left(4 \pm 2{ }^{\circ} \mathrm{C}\right)$ ou freezer $\left(-14,5 \pm 2{ }^{\circ} \mathrm{C}\right)$. Foi utilizado o delineamento experimental inteiramente casualizado e os tratamentos foram arranjados em esquema fatorial 3 (condições de temperatura) x 6 (períodos de armazenamento) com três repetições. A viabilidade das sementes foi determinada através do teste de tetrazólio. Para a aclimatização, plantas com dois anos, oriundas de semeadura in vitro, foram aclimatizadas em bandejas plásticas contendo: 1- esfagno; 2- carvão ou 3- fibra de coco. Foi utilizado o delineamento experimental inteiramente casualizado com 3 tratamentos e 4 repetições de 10 plantas cada. As plantas permaneceram por 365 dias em viveiro, sob condições ambientais e recebendo luminosidade média diária de $130 \mu \mathrm{mol} \mathrm{m} \mathrm{m}^{-2}$ $\mathrm{s}^{-2}$. Após esse período, as plantas foram avaliadas quanto à porcentagem de sobrevivência, de massa fresca e seca da parte aérea e das raízes, sendo também calculadas as relações entre a massa fresca das plantas, o comprimento da parte aérea e da maior raiz, o número de raízes e o número de perfilhos, observados no final do período experimental em relação àqueles registrados no plantio. Após 84 dias sementes armazenadas em condições ambientais apresentaram $0,0 \%$ de viabilidade, enquanto que aquelas armazenadas em refrigerador e em freezer apresentaram 77,6 e 67,2 \% de viabilidade. Ao final do período de aclimatização, todas as relações entre os valores iniciais e finais foram superiores a 1,00 indicando que as condições apresentadas pelos três substratos propiciaram o crescimento da espécie, sendo a porcentagem de sobrevivência das plantas em torno de $89 \%$. Conclui-se que sementes de $B$. tuberculata devam ser armazenadas em refrigerador e que os substratos estudados podem ser utilizados na aclimatização de plantas de $B$. tuberculata.

Palavras-chave: Orquídeas, substratos, viabilidade de sementes

\footnotetext{
Abstract

In vitro sowing and acclimatization of the produced plantlets are responsible factors for the successful production of Orchidaceae. This study aimed to: 1) evaluate the viability of $B$. tuberculata seeds stored

${ }^{1}$ Dr $^{\mathrm{a}}$ em Agronomia, Universidade Federal da Grande Dourados, UFGD, Dourados, MS. E-mail: marichelcanazza@yahoo.com.br

2 Discente do Curso de Doutorado do Programa de Pós-Graduação em Agronomia, UFGD, Dourados, MS. E-mail: derekrosa@,

3 Discente do Curso de Doutorado do Programa de Pós-Graduação em Recursos Naturais, Universidade Estadual de Mato Grosso do Sul, UEMS, Dourados, MS. E-mail: jacke.schultz@gmail.com

4 Técnicas de Laboratório, UFGD, Dourados, MS. E-mail: marianatatara@gmail.com; nildahoffmmann@ufgd.edu.br

${ }^{5}$ Prof $^{\mathrm{a}}$, Faculdade de Ciências Agrárias, FCA, UFGD, Dourados, MS. E-mail: yararosa@ufgd.edu.br

* Autor para correspondência
} gmail.com 
at different temperatures, and 2) evaluate the ex vitro growth of $B$. tuberculata on different substrates. The seeds were stored for 84 days under three conditions: ambient temperature $\left(23 \pm 2^{\circ} \mathrm{C}\right)$, refrigerator $\left(4 \pm 2{ }^{\circ} \mathrm{C}\right)$ or freezer $\left(-14.5 \pm 2{ }^{\circ} \mathrm{C}\right)$. The completely randomized design was used and treatments were arranged in a 3 (temperature conditions) x 6 (storage period) factorial scheme with three replications. Seed viability was determined by tetrazolium test. For acclimatization, two-year plants coming from in vitro sowing were acclimatized in plastic trays containing: 1 - sphagnum; 2 - charcoal or 3 - coconut fiber. We used the completely randomized design with 3 treatments and 4 replications of 10 plants each. The plants remained in the greenhouse for 365 days under ambient conditions, receiving daily average brightness of $130 \mu \mathrm{m}^{-2} \mathrm{~s}^{-2}$. After this period, the plants were evaluated for survival percentage, fresh and dry weight of shoots and roots, and it was calculated the relationship between fresh weight of the plants, the shoot length and the largest root, the number roots and the number of tillers, observed at the end of the experimental period compared to those recorded at planting. For the seed study, after 84 days seeds stored under ambient conditions showed $0.0 \%$ viability, while those stored in the refrigerator and freezer showed 77.6 and $67.2 \%$ viability. At the end of the acclimatization period, all the relations between the initial and final values were greater than 1.00 indicating that the conditions presented by the three substrates led to the growth of the species, and the percentage of plant survival was around $89 \%$. We conclude that the $B$. tuberculata seeds should be stored in the refrigerator and that the studied substrates can be used in the acclimatization plants of $B$. tuberculata.

Key words: Orchids, substrates, seeds viability

\section{Introdução}

A família Orchidaceae representa $7 \%$ das espécies da flora do planeta. Estão catalogadas cerca de 35 mil espécies, distribuídas em mais de 2500 gêneros, além dos híbridos naturais e artificiais (ALTAFIN et al., 2003). As espécies dessa família botânica distribuem-se por quase todas as regiões (exceção para as polares e desérticas), concentramse mais em florestas úmidas de regiões tropicais e subtropicais e apresentam hábito terrícola, rupícola, epífita ou saprofita (MATTIUZ; RODRIGUES; MATTIUZ, 2006).

Muitas espécies de orquídeas estão desaparecendo de seus habitats, devido ao extrativismo, comércio ilegal e destruição dos ecossistemas onde estão inseridas (MULLER et al., 2007). Nesse sentido, a conservação de sementes e a produção de mudas de orquídeas são alternativas de preservação e ambas dependem de sementes viáveis (MELLO, 2000).

Os frutos produzidos pelas orquídeas apresentam numerosas sementes, com tamanho e peso reduzidos, o que torna o estabelecimento de um banco genético através do seu armazenamento bastante indicado, tanto para espécies silvestres, quanto para espécies já melhoradas (VIEIRA; CARVALHO, 1994).
O armazenamento adequado de sementes além de favorecer a eficiência do processo produtivo pode ser usado na conservação de recursos genéticos ex situ, ocupando pequenos espaços, por longos períodos de tempo e a menores custos (MELLO, 2000). No entanto, não há na literatura informações conclusivas sobre as melhores condições de armazenamento de sementes de orquídeas.

Tão importante quanto as condições do armazenamento é a identificação da viabilidade das sementes. Para tal, o teste de tetrazólio é considerado eficiente e rápido, possibilitando a avaliação da viabilidade do material para fins de semeadura (KRZYZANOWISKI; VIEIRA; FRANÇA NETO, 1999), sendo utilizado para orquídeas (ALVAREZPARDO; FERREIRA, 2006; HOSOMI et al., 2012; MWEETWA; WELBAUM; TAY, 2007; SOARES et al., 2012a, 2012b, 2013)

As técnicas de cultivo in vitro são empregadas na produção de orquídeas uma vez que possibilitam rápida multiplicação em relação aos métodos convencionais produzindo mudas em maior quantidade e qualidade fitossanitária (BOSA et al., 2003). Entretanto, o processo de transferência das mudas da condição in vitro para a condição ex vitro, denominado aclimatização, constitui um dos 
maiores limites dessa técnica (GRATTAPAGLIA; MACHADO, 1998).

Desta forma, é necessário que a planta, em aclimatização, seja cultivada em substrato que propicie condições físicas, químicas e biológicas necessárias ao seu desenvolvimento (KÄMPF, 2000; LONE et al., 2008). Em sua revisão, Ferraz, Centurion e Beutler (2005) salienta que os substratos usualmente empregados na horticultura são de origem vegetal, mineral ou sintética, sendo a turfa e a vermiculita os mais utilizados. Já para a aclimatização de plantas produzidas in vitro, o esfagno é o mais utilizado, devido a sua alta capacidade de retenção de água e por sua textura macia não causar danos ao sistema radicular das plantas. Entretanto, devido à coleta indiscriminada, encontra-se em risco de extinção (SOUZA, 2003), e os cultivos comerciais ainda não suprem a demanda do mercado, o que justifica a procura por materiais que possam substituí-lo.

A casca de coco verde (subproduto do uso e da industrialização de água de coco) processada para beneficiamento de fibras longas, curtas ou pó, tem sido utilizada como substrato no cultivo de orquídeas (ASSIS et al., 2005, 2008; MACEDO et al., 2011; YAMAKAMI; FARIA; STENZEL, 2009). De maneira análoga, o fino do carvão (subproduto da produção de carvão vegetal) é utilizado como substrato ou em misturas (ZANETTI et al., 2003), sendo recomendado no cultivo das orquídeas Dendrobium phalaenopsis (MACEDO et al., 2011) e Dendrobium nobile, neste último caso, em mistura com Plantmax + isopor (MORAES; CAVALCANTE; FARIA, 2002).

Brassavola tuberculata é uma espécie anual que ocorre no estado de Mato Grosso do Sul onde é conhecida popularmente como "chuva de prata, cebolinha, rabo de rato e orquídea dama-da-noite". Possui elevado valor ornamental, uma vez que apresenta florada abundante e duradoura, que se estende de junho até setembro, com o pico de floração em agosto. Produz inflorescências contendo cinco a sete flores de coloração branca levemente amarela, que exalam odor levemente adocicado ao anoitecer. (RECH; ROSA; MANENTE-BALESTIERE, 2010). O gênero Brassavola juntamente com os gêneros Cattleya, Laelia e Sophronites (EIGELDINGER; MURPHY, 1972) se intercruzam originando plantas com características morfológicas mais interessantes que os parentais e, devido à beleza de suas flores, são os mais ameaçados pelas coletas predatórias (HERING; PUTZKE, 2007).

Este trabalho teve como objetivos: 1) avaliar a viabilidade das sementes de $B$. tuberculata armazenadas em diferentes temperaturas e 2) avaliar o crescimento ex vitro de $B$. tuberculata em diferentes substratos.

\section{Material e Métodos}

O trabalho foi desenvolvido no Laboratório de Cultivo in vitro e na área de Jardinocultura da Faculdade de Ciências Agrárias (FCA) da Universidade Federal da Grande Dourados (UFGD), durante o período de abril de 2009 a abril de 2010. Dois experimentos independentes foram realizados:

Armazenamento de sementes de Brassavola tuberculata

Foram utilizados 20 frutos de B. tuberculata, oriundos de polinização natural, colhidos, de cinco plantas matrizes, com 12 anos de idade, pertencentes ao acervo da área de Jardinocultura da FCA. Os frutos foram colhidos oito meses após o término do período de florescimento e, na sequência, foram transferidos para o laboratório de cultivo in vitro onde foram lavados com detergente neutro, e avaliados quanto aos aspectos biométricos, apresentando massa fresca de 0,89 $\pm 0,45 \mathrm{~g}$, comprimento de $1,92 \pm 0,32 \mathrm{~cm}$ e largura na porção mais dilatada do ovário de $0,95 \pm 0,20 \mathrm{~cm}$.

Os frutos foram abertos, com auxílio de um estilete, suas sementes foram removidas com auxílio 
de uma espátula e colocadas em placa de Petri, onde foram homogeneizadas. Três amostras de $0,005 \mathrm{~g}$ dessas sementes foram retiradas e submetidas ao teste de tetrazólio (solução aquosa a $0,5 \%$ ) para a determinação da viabilidade inicial, resultando em $100 \%$ de sementes viáveis.

As demais sementes foram mantidas em dessecador com sílica gel, durante 14 dias, em ambiente provido de luz fluorescente branca (20,0 $\mu \mathrm{mol} \mathrm{m} \mathrm{m}^{-2} \mathrm{~s}^{-1}$ ), com fotoperíodo e temperatura controlados $\left(12 \mathrm{~h} 00 ; 23 \pm 2{ }^{\circ} \mathrm{C}\right)$. Decorrido esse período, três amostras de $0,005 \mathrm{~g}$ de sementes foram submetidas ao teste de tetrazólio, para nova avaliação da sua viabilidade, que resultou 97,0\%. $\mathrm{O}$ restante das sementes foi dividido em porções de 0,005 g cada, embaladas em papel alumínio e cada porção foi armazenada em frasco de polipropileno branco provido de tampa com sílica gel, por até 84 dias, sob três condições de temperatura (ambiente $=$ $23 \pm 2{ }^{\circ} \mathrm{C}$; refrigerador $=4 \pm 2{ }^{\circ} \mathrm{C}$ e freezer $=-14 \pm 2$ $\left.{ }^{\circ} \mathrm{C}\right)$. A cada 14 dias três amostras de $0,005 \mathrm{~g}$ de cada tratamento foram submetidas ao teste de tetrazólio. No total, foram realizadas seis avaliações, aos 14 , $28,42,56,70$ e 84 dias após o armazenamento das sementes.

O teste de tetrazólio foi realizado conforme procedimentos descritos por Rech, Rosa e ManenteBalestiere (2010) em que as amostras de sementes foram colocadas em tubos de ensaio, acrescidas de $3 \mathrm{~mL}$ de solução aquosa $(0,5 \%)$ de cloreto de 2,3 , 5 trifeniltetrazolio e acondicionadas em ambiente desprovido de luz, por 24 horas. Após esse período, as amostras foram acrescidas de $7 \mathrm{~mL}$ de água destilada e agitadas para a realização das contagens.

As contagens foram realizadas com auxílio de um microscópio estereoscópico a partir de amostras de $1 \mathrm{~mL}$, utilizando-se a câmara de contagem de Peters. Foi contado o número de sementes portadoras de embriões totalmente coloridos de carmim, consideradas viáveis conforme Lauzer, St-Arnaud e Barabé (1994), e o número de sementes total da suspensão. A porcentagem de sementes viáveis
$(\% \mathrm{SV})$ foi determinada pela seguinte fórmula: $\% \mathrm{SV}$ $=\left[\left(\mathrm{N}^{\mathrm{o}}\right.\right.$ de sementes com embriões carmim x 100)/ $\mathrm{N}^{\circ}$ total de sementes da suspensão].

Foi utilizado o delineamento experimental inteiramente casualizado, e os tratamentos foram arranjados em esquema fatorial 3 x 6 (três condições de temperaturas e seis períodos de armazenamento), com 3 repetições. Os dados de $\% \mathrm{SV}$ foram transformados para $V_{\mathrm{x}}+1 \mathrm{e}$, a seguir, foram submetidos à análise de variância pelo teste $\mathrm{F}$, até $5 \%$ de probabilidade. Os fatores qualitativos, quando significativos, foram comparados por teste de médias (Tukey, até 5\% de probabilidade) e os quantitativos por regressão, com a utilização do aplicativo computacional SISVAR 5.3 (FERREIRA, 2011).

\section{Aclimatização de Brassavola tuberculata}

Como material de estudo foram utilizadas plantas de $B$. tuberculata oriundas de semeadura in vitro, que permaneceram, por dois anos, em sala de crescimento, sob temperatura de $25 \pm 2{ }^{\circ} \mathrm{C} \mathrm{e}$ fotoperíodo de 12 horas $\left(20 \mu \mathrm{mol} \mathrm{m} \mathrm{m}^{-2} \mathrm{~s}^{-1}\right)$ produzido por duas lâmpadas fluorescentes brancas, de $40 \mathrm{~W}$ cada. Essas plantas foram cultivadas em meio de cultura alternativo composto por $70 \mathrm{~g}$ de tomate tipo italiano, variedade Santa Cruz, maduros, vermelhos, sem cascas e sementes, $50 \mathrm{~g}$ de banana nanica amarelada, sem casca (provenientes de cultivo convencional), $3 \mathrm{~mL}$ de adubo NPK na formulação 10-10-10, 17 g de ágar bacteriológico, $25 \mathrm{~g}$ de açúcar cristal, 3,0 g de carvão ativado, 150 $\mathrm{mL}$ de água de coco e água destilada para completar um litro (CAMPOS, 2002; SOARES et al., 2012a). Durante esse período, foram realizados quatro subcultivos, sendo mantidas 20 plantas por frasco.

Após esse período, as plantas foram retiradas dos frascos de cultivo, lavadas com água corrente e avaliadas quanto à massa fresca e comprimento da parte aérea. A seguir, plantas providas de raízes $(2,0 \pm 0,23)$ e de perfilhos $(2,0 \pm 0,17)$, com comprimento da parte aérea em torno de $2,5 \pm 0,31$ 
$\mathrm{cm}$ e de maior raiz $1,8 \pm 0,25 \mathrm{~cm}$ e massa fresca em torno de $0,19 \pm 0,02 \mathrm{~g}$, foram transplantadas em bandejas de polipropileno com 40 células de $75 \mathrm{~cm}^{3}$ cada, contendo os seguintes substratos: 1- esfagno ; 2- carvão (de diâmetro entre 5 e 10 mm) e 3-fibra de coco (Golden-Mix Chips da Amafibra $\left.{ }^{\circledR}\right)$.
Os substratos foram caracterizados quanto aos seus atributos físicos (macro, microporosidade, porosidade total, capacidade máxima de retenção de água e densidade) e químicos ( $\mathrm{pH}$ e condutividade elétrica), segundo metodologia proposta por Guerrini e Trigueiro (2004), e os valores obtidos constam da Tabela 1.

Tabela 1. Macroporosidade (MA), microporosidade (MI), porosidade total (PT), densidade (D), pH em água e condutividade elétrica (CE) dos substratos. UFGD, Dourados-MS, 2009.

\begin{tabular}{lccccccc}
\hline Substrato & $\begin{array}{c}\text { MA } \\
\left(\mathrm{m}^{3} \mathrm{~m}^{-3}\right)\end{array}$ & $\begin{array}{c}\text { MI } \\
\left(\mathrm{m}^{3} \mathrm{~m}^{-3}\right)\end{array}$ & $\begin{array}{c}\text { PT } \\
\left(\mathrm{m}^{3} \mathrm{~m}^{-3}\right)\end{array}$ & $\begin{array}{c}\mathbf{C M R} \\
\left(\mathrm{m}^{3} \mathrm{~m}^{-3}\right)\end{array}$ & $\begin{array}{c}\mathbf{D} \\
\left(\mathrm{kg} \mathrm{dm}^{-3}\right)\end{array}$ & $\begin{array}{c}\mathbf{p H} \\
\left(\mathrm{H}_{2} \mathrm{O}\right)\end{array}$ & $\begin{array}{c}\mathbf{C E} \\
\left(\mu \mathrm{Scm}^{-1}\right)\end{array}$ \\
\hline Esfagno & 75,8 & 23,8 & 99,6 & 11,8 & 0,01 & 5,8 & 250,0 \\
Fibra de coco & 58,5 & 28,5 & 87,0 & 14,3 & 0,06 & 6,0 & 260,0 \\
Carvão & 53,9 & 19,5 & 73,5 & 9,7 & 0,20 & 8,0 & 1300,0 \\
\hline
\end{tabular}

Fonte: Elaboração dos autores.

Após o transplante as bandejas, contendo os substratos e as plantas, foram acondicionadas em viveiro coberto pela sobreposição de três telas de sombreamento de $50 \%$ cada (que propiciaram luminosidade média diária de $130 \mu \mathrm{mol} \quad \mathrm{m}^{-2}$ $\left.\mathrm{s}^{-2}\right)$, sob condições médias de temperatura e umidade relativa de $22,6 \pm 5{ }^{\circ} \mathrm{C}$ e $73,9 \pm 10 \%$, respectivamente. $\mathrm{O}$ sistema de irrigação utilizado durante o período experimental foi constituído de difusores, posicionados um metro acima das plantas, acionados automaticamente por temporizador digital e válvula solenóide. Foram realizadas quatro irrigações diárias, que totalizaram uma lâmina de água de $2 \mathrm{~mm} \mathrm{dia}{ }^{-1}$. As plantas foram adubadas quinzenalmente, via foliar, com NPK 10-10-10 na concentração de $2,0 \mathrm{~mL} \mathrm{~L}^{-1}$ e desinfestadas preventivamente, a cada 30 dias, com O,S-dimetil$\mathrm{N}$-acetil-fosforamidotioato (4 $\left.\mathrm{mg} \mathrm{L}^{-1}\right)$ e Mancozebe (4 $\left.\mathrm{mg} \mathrm{L}^{-1}\right)$.

No final do experimento, plantas vivas e mortas foram contabilizadas para a determinação da porcentagem de sobrevivência $(\% \mathrm{~S})$. As plantas sobreviventes foram retiradas dos substratos e lavadas em água corrente até total remoção dos mesmos. Na sequência foram pesadas para determinação da massa fresca e, em seguida, foram avaliadas quanto ao comprimento da parte aérea, comprimento da maior raiz, número de raízes e número de perfilhos, Após essas avaliações, as plantas foram separadas, com auxílio de um bisturi, em parte aérea e sistema radicular, e depois de determinadas a massa fresca e seca dessas partes foram calculados os seus valores porcentuais em relação às massas fresca e seca das plantas.

Dado o interesse em investigar a hipótese de aumento nos valores de massa fresca das plantas, comprimento da parte aérea e da maior raiz, do número de raízes e do número de perfilhos, observados no final do período experimental (VF), em relação àqueles registrados no plantio (VP), foram calculados suas relações (R), por meio da expressão $\mathrm{R}=\mathrm{VF} / \mathrm{VP}$ sendo estes os valores considerados nas análises estatísticas, juntamente com as porcentagens de sobrevivência, de massa fresca e seca da parte aérea e das raízes.

Para a determinação do comprimento da parte aérea e da maior raiz foi utilizado paquímetro digital graduado em milímetros. Para a obtenção das massas secas, os materiais foram secos em estufa de circulação forçada de ar a $65 \pm 2{ }^{\circ} \mathrm{C}$, até peso constante. 
O delineamento experimental utilizado foi o inteiramente casualizado com três tratamentos e quatro repetições de 10 plantas. Os resultados decorrentes de variáveis discretas ou de porcentagem foram transformados para $\sqrt{\mathrm{x}}+1 \mathrm{e}$, a seguir, foram submetidos à análise de variância pelo teste $\mathrm{F}$ até 5\% de probabilidade. Havendo diferenças significativas, as médias foram comparadas por teste de Tukey até 5\% de probabilidade com a utilização do aplicativo computacional SISVAR 5.3 (FERREIRA, 2011).

\section{Resultados e Discussão}

Armazenamento de sementes de Brassavola tuberculata

Houve efeito isolado e conjunto dos fatores estudados $(p<0,01)$ sobre a porcentagem de sementes viáveis $(\% \mathrm{SV})$ de $B$. tuberculata (Tabela 2). Em relação às condições de armazenamento, o armazenamento em refrigerador proporcionou a maior porcentagem de sementes viáveis $(86,1 \%)$, seguido do armazenamento em freezer $(80,7 \%)$ e este do armazenamento em condições ambientais (42,1\%) (Tabela 3).

Tabela 2. Resumo da análise de variância da porcentagem de sementes viáveis (\%SV) de Brassavola tuberculata Hook (Orchidaceae). UFGD, Dourados - MS, 2009.

\begin{tabular}{lcc}
\hline & & Quadrados médios \\
\cline { 3 - 3 } Fontes de Variação & G.L. & \%SV \\
\hline Período de armazenamento & 5 & $2178,02^{* *}$ \\
Condição de temperatura & 2 & $10359,51^{* *}$ \\
P. armazenamento x C. temperatura & 10 & $954,25^{* *}$ \\
Resíduo & 36 & 29,58 \\
\hline CV (\%) & & 7,81 \\
Média Geral & & 69,62 \\
\hline
\end{tabular}

** significativo, a $1 \%$ de probabilidade, pelo teste $\mathrm{F}$.

Fonte: Elaboração dos autores.

Tabela 3. Porcentagem de sementes viáveis (\%SV) de Brassavola tuberculata Hook (Orchidaceae) em função do armazenamento em diferentes temperaturas. UFGD, Dourados - MS, 2009.

\begin{tabular}{cc}
\hline Condições de temperatura & \%SV \\
\hline Temperatura ambiente $\left(23 \pm 2{ }^{\circ} \mathrm{C}\right)$ & $42,09 \mathrm{c}$ \\
Refrigerador $\left(4 \pm 2{ }^{\circ} \mathrm{C}\right)$ & $86,05 \mathrm{a}$ \\
Freezer $\left(-14 \pm 2{ }^{\circ} \mathrm{C}\right)$ & $80,73 \mathrm{~b}$ \\
\hline
\end{tabular}

Médias seguidas pela mesma letra não diferem entre si (Tukey, $5 \%$ de probabilidade).

Fonte: Elaboração dos autores.

Durante o período de armazenamento houve perda da viabilidade das sementes para todas as condições estudadas. Aos 82 dias de armazenamento, as sementes mantidas em condições ambientais já não se apresentaram viáveis, enquanto que aquelas armazenadas em refrigerador ou freezer, após 84 dias de armazenamento, ainda apresentaram viabilidade de 77,6 e $67,2 \%$ respectivamente (Figura 1). 
Figura 1. Valores porcentuais da viabilidade de sementes de Brassavola tuberculata Hook (Orchidaceae) em função do período e das condições de armazenamento. UFGD, Dourados - MS, 2009. TA = armazenamento em temperatura ambiente $23 \pm 2{ }^{\circ} \mathrm{C}$; $\mathrm{RF}=$ armazenamento em refrigerador $4 \pm 2{ }^{\circ} \mathrm{C}$ e $\mathrm{FR}=$ armazenamento em freezer $-14 \pm 2{ }^{\circ} \mathrm{C}$.

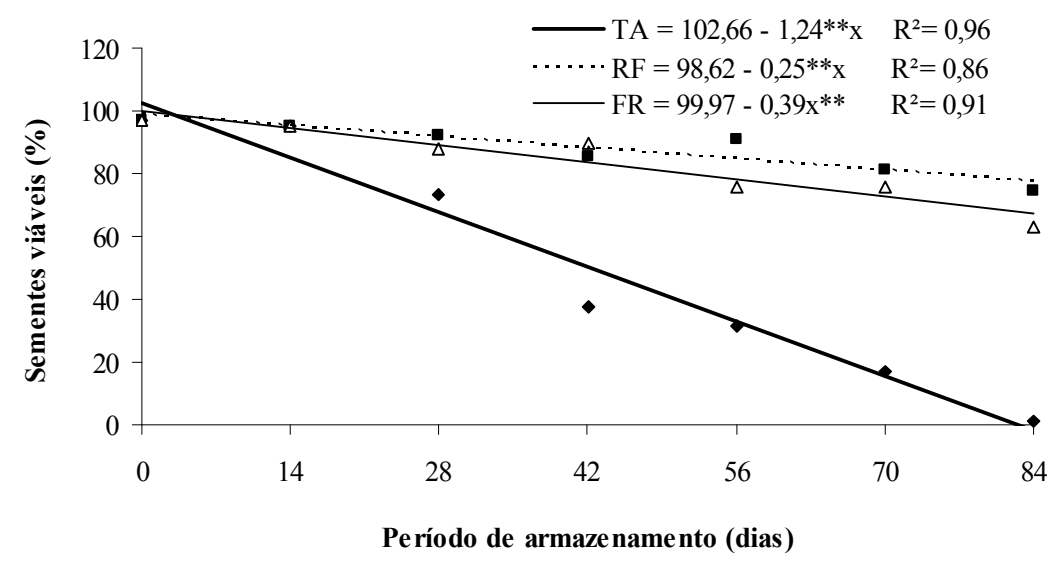

Fonte: Elaboração dos autores.

Em temperatura ambiente foi observado um rápido decréscimo da $\% \mathrm{SV}$ ao longo do período experimental, enquanto que as perdas relatadas nas duas outras condições de temperatura foram mais lentas, sugerindo o armazenamento das sementes por maiores períodos (Figura 1). Hosomi et al. (2012) relatam decréscimos na viabilidade de sementes de Cattleya sanguiloba, quando armazenada a $-18{ }^{\circ} \mathrm{C}$, por três meses. Entretanto o autor salienta que para outras espécies do gênero (C. mossai, $C$. intermedia, C. hegeriana, C. leopoldii, C. purpurata e $C$. walkeriana) as mesmas condições propiciaram aumento na viabilidade das sementes quando comparadas aos valores iniciais, indicando que as condições de armazenamento estudadas ainda não permitem uma generalização desse procedimento para orquídeas.

Os resultados observados neste trabalho para o armazenamento em condições ambientais podem ser explicados pelos relatos de Aguiar (1995) nos quais o autor salienta que a umidade relativa do ar e a temperatura do ambiente de armazenamento são os principais fatores que afetam a qualidade das sementes durante esse processo. Considerando que neste estudo, as sementes foram armazenadas em recipientes fechados e providos de sílica gel, pode-se inferir que estes resultados foram mais influenciados pela temperatura de armazenamento do que pela umidade.

Aguiar (1995) ainda salienta que elevada umidade relativa do ar pode proporcionar o reinício das atividades metabólicas do embrião, enquanto que temperaturas elevadas ocasionam aumento da atividade respiratória e esgotamento das substâncias de reserva acumuladas o que pode ter ocorrido nas sementes armazenadas em temperatura ambiente.

O efeito benéfico do armazenamento de sementes de orquídeas em ambientes com baixa temperatura $\left(5^{\circ} \mathrm{C}\right)$ e baixa umidade relativa $(6 \%)$ foi relatado por Pardo e Ferreira (2006) para diversas espécies mantendo sua viabilidade próxima a $100 \%$ após 12 meses de armazenamento. Martins e Lago (2008) também salientam que a umidade e a temperatura influenciam as reações bioquímicas que regulam o metabolismo envolvido na conservação das sementes. A redução de ambas segundo Vieira et al. (2001) faz com que o metabolismo das sementes seja reduzido e que microorganismos presentes nas mesmas não tenham condições de se desenvolver, mantendo sua longevidade.

Acredita-se que a longevidade de sementes de orquídeas armazenadas aumente quando o teor 
de umidade situa-se entre 5 a 10\% (MUGAMBI; WOOD, 2002). Alguns estudos têm demonstrado que, conquanto as sementes de orquídeas sejam secas corretamente, é provável que possam permanecer viáveis por muitas décadas quando armazenadas sob temperatura de $-20^{\circ} \mathrm{C}$ (SEATON; PRITCHARD, 2011).

Os resultados observados neste estudo corroboram as suposições científicas que sugerem que sementes de orquídeas apresentem comportamento semelhante aos das sementes ortodoxas, podendo ser armazenadas com um baixo teor de umidade e temperatura, o que conservaria sua viabilidade por um maior período (PARDO; FERREIRA, 2006).

\section{Aclimatização de plantas de Brassavola tuberculata} Hook

Houve efeito significativo dos substratos $(p<0,05)$ apenas para a porcentagem de massa fresca da parte aérea (\%MFPA) e das raízes (\%MFR). Para as demais variáveis analisadas não houve influência dos substratos $(p>0,05)$, e suas médias gerais são apresentadas na Tabela 4 .

A porcentagem de sobrevivência média foi de $80 \%$ (Tabela 4) valores estes considerados satisfatórios para a fase de aclimatização, principalmente em se tratando de espécie nativa, oriunda de semeadura in vitro que, devido à variabilidade genética, apresentam indivíduos que se adéquam mais ou menos às condições ex vitro.

Todas as relações entre os valores iniciais e finais foram superiores a 1,00 indicando que as condições apresentadas pelos três substratos propiciaram o crescimento da espécie, sendo que os maiores incrementos (em torno de 4,0) foram observados para o número de raízes e para o número de perfilhos (Tabela 4). Esses resultados permitem inferir que as plantas de $B$. tuberculata, quando aclimatizadas em esfagno, fibra de coco ou carvão, tendem a investir primeiramente em estruturas capazes de absorver água e nutrientes (raízes) e em estruturas capazes de armazená-los (perfilhos), para posteriormente promover incrementos em massa, comprimento da parte aérea e do sistema radicular.

Os maiores valores de \%MFPA foram observados nas plantas cultivadas em carvão (42,7\%), entretanto esse substrato apresentou também os menores valores de \%MFR (57,3\%). Já o esfagno e a fibra de coco apresentaram comportamento contrário ao do carvão, apresentando menores valores de \%MFPA $(32,9$ e $32,4 \%)$ e maiores valores de $\% \operatorname{MFR}(67,1$ e $67,6 \%$ ), respectivamente (Tabela 4).

Os maiores de \%MFPA e \%MFR observados em plantas cultivadas em carvão devem-se provavelmente à porosidade, $\mathrm{pH}$ e condutividade elétrica desse substrato. Dos substratos estudados, o carvão é o que apresenta os menores valores de microporosidade e de capacidade máxima de retenção de água, e os maiores valores de $\mathrm{pH}$ e condutividade elétrica (Tabela 1).

Um dos fatores abióticos que mais condiciona o sucesso da aclimatização de plantas ex vitro é a disponibilidade de água. Embora $B$. tuberculata seja epífita, com sistema radicular provido de velame (estrutura armazenadora de água), o fato de o carvão apresentar menores valores de microporosidade e capacidade de retenção de água pode ter induzido a planta a armazená-la nos perfilhos, (parte aérea) uma vez que o substrato não se mantinha úmido por período igual aos demais substratos estudados. Essa teoria se fundamenta no fato de não haver diferenças estatísticas entre as \%MSPA e \%MSR das plantas cultivadas nos três substratos (Tabela 4), sendo, portanto, as diferenças entre as \%MFPA e \%MSR decorrentes o teor de água armazenado. 
Tabela 4. Valores das relações entre massa fresca final e inicial (RMF), comprimento inicial e final da parte aérea (RCPA), comprimento da maior raiz inicial e final (RCMR), número de raízes inicial e final (RNR) e número de perfilhos inicial e final (RNP), porcentagem de massa fresca da parte aérea (\%MFPA) e das raízes (\%MFR), porcentagem de massa seca da parte aérea (\%MSPA) e das raízes (\%MSR) e porcentagem de sobrevivência $(\% \mathrm{~S})$ de plantas de Brassavola tuberculata Hook (Orchidaceae) em função dos substratos estudados. UFGD, Dourados- MS, 2009.

\begin{tabular}{llllll}
\hline Substrato & RMF & RCPA & RCMR & RNR & RNP \\
\hline Esfagno & $2,9 \mathrm{a}$ & $1,7 \mathrm{a}$ & $1,7 \mathrm{a}$ & $4,1 \mathrm{a}$ & $3,4 \mathrm{a}$ \\
Fibra de coco & $3,0 \mathrm{a}$ & $1,5 \mathrm{a}$ & $1,8 \mathrm{a}$ & $4,3 \mathrm{a}$ & $4,4 \mathrm{a}$ \\
Carvão & $2,6 \mathrm{a}$ & $1,5 \mathrm{a}$ & $1,8 \mathrm{a}$ & $4,7 \mathrm{a}$ & $4,1 \mathrm{a}$ \\
Média & 2,8 & 1,6 & 1,8 & 4,4 & 4,0 \\
CV(\%) & 14,3 & 6,1 & 4,0 & 4,0 & 7,4 \\
F & $0,03^{\text {ns }}$ & $0,23^{\text {ns }}$ & $0,36^{\text {ns }}$ & $1,79^{\text {ns }}$ & $2,12^{\text {ns }}$ \\
Desvio Padrão & 0,97 & 0,29 & 0,21 & 0,46 & 0,77 \\
Valores médios finais & MF $=0,5 \mathrm{~g}$ & CPA $=3,9 \mathrm{~cm}$ & CMR $=3,3 \mathrm{~cm}$ & $\mathbf{N R}=8,9$ & $\mathrm{NP}=8,0$ \\
& & & & & \\
\hline Substrato & $\mathbf{\% M F P A}$ & $\mathbf{\% M F R}$ & $\mathbf{\% M S P A}$ & $\mathbf{\% M S R}$ & $\mathbf{\% S}$ \\
\hline Esfagno & $32,9 \mathrm{~b}$ & $67,1 \mathrm{a}$ & $40,5 \mathrm{a}$ & $59,4 \mathrm{a}$ & $67,5 \mathrm{a}$ \\
Fibra de coco & $32,4 \mathrm{~b}$ & $67,6 \mathrm{a}$ & $37,6 \mathrm{a}$ & $62,4 \mathrm{a}$ & $87,5 \mathrm{a}$ \\
Carvão & $42,7 \mathrm{a}$ & $57,3 \mathrm{~b}$ & $45,6 \mathrm{a}$ & $54,4 \mathrm{a}$ & $85,5 \mathrm{a}$ \\
Média & 36,0 & 64,0 & 41,2 & 58,7 & 80,2 \\
CV(\%) & 6,3 & 3,4 & 8,4 & 6,0 & 8,4 \\
F & $0,02^{*}$ & $7,07^{*}$ & $1,36^{\mathrm{ns}}$ & $1,24^{\text {ns }}$ & $2,99^{\text {ns }}$ \\
Desvio Padrão & 6,41 & 6,41 & 7,30 & 7,30 & 14,77 \\
\hline
\end{tabular}

Médias seguidas de mesma letra, na coluna, não diferem entre si (Tukey, $5 \%$ de probabilidade)

* significativo a 5\% de probabilidade pelo teste $\mathrm{F}$; ${ }^{\text {ns }}$ não significativo pelo teste $\mathrm{F}$.

Fonte: Elaboração dos autores.

Em relação ao $\mathrm{pH}$ e à condutividade elétrica, embora exista grande variabilidade nos relatos científicos para o cultivo Orchidaceae, em função do genótipo estudado, os valores de $\mathrm{pH}$ apresentados pelo carvão podem causar indisponibilidade de absorção de micronutrientes (EPSTEIN; BLOOM, 2006) e os valores de condutividade elétrica caracterizam substratos inadequados ao cultivo de orquídeas epífitas que, segundo Segundo Takane, Faria e Altafin (2006), não deve ser superior 500,0 $\mu \mathrm{S} \mathrm{cm}^{-1}$.

Existem orquídeas que se desenvolveram adequadamente em $\mathrm{pH}$ em torno de 3,5 e outros em pH em torno de 7,0 (DRONK et al., 2012; KÄMPF, 2000) assim como foram identificadas plantas que se desenvolveram igualmente em condutividade elétrica variando de 65,6 a $213,9 \mu \mathrm{S} \mathrm{cm}^{-1}$ (LONE et al., 2010; DRONK et al., 2012). As plantas $B$. tuberculata apresentaram os maiores resultados de \%MFR em substratos cujo $\mathrm{pH}$ variou de 5,8 a 6,0 e condutividade elétrica entre 250,0 e $260,0 \mu \mathrm{S} \mathrm{cm}^{-1}$ (Tabela 1).

A condutividade elétrica registrada para o carvão $\left(1300,0 \mu \mathrm{S} \mathrm{cm}^{-1}\right)$ foi de cinco vezes maior que aquelas observadas para o esfagno e a fibra de coco, e os teores de sais contidos naquele substrato provavelmente ocasionaram perdas de água pelo sistema radicular (TAKANE; FARIA; ALTAFIN, 2006) o que também pode justificar a menor \%MFR de plantas $B$. tuberculata cultivadas nesse substrato.

Já as plantas que foram cultivadas em esfagno ou fibra de coco apresentaram maiores valores porcentuais de massa fresca no sistema radicular em relação à parte aérea (Tabela 4). Além de apresentarem menores valores de $\mathrm{pH}$ e de condutividade elétrica, apresentam também maiores 
valores de microporosidade e capacidade de retenção de água que o carvão, propiciando fornecimento de água em níveis mais favoráveis à espécie, mantendo a hidratação dos velames e favorecendo a retenção de água no sistema radicular, sendo, portanto mais adequados à fase de aclimatização de $B$. tuberculata.

Embora com diferentes texturas e níveis de plasticidade, os três substratos estudados não causaram danos aos sistemas radiculares das plantas a serem aclimatizadas, uma vez as mesmas apresentaram número médio de raízes em torno de 8,9 e comprimento médio da maior raiz de $3,3 \mathrm{~cm}$, valores estes que propiciaram relações positivas de 4,4 e 1,8, respectivamente, entre os valores finais e os do início da aclimatização (Tabela 4).

Como para as demais características estudadas não foram observados efeitos significativos dos substratos e, ao final do período experimental, as relações entre os valores finais e iniciais das variáveis estudadas foram todos positivos (Tabela 4), pode-se inferir a fibra de coco ou o carvão também são indicados como substratos para aclimatização de plantas de $B$. tuberculata, pois apresentam as condições necessárias ao crescimento e desenvolvimento das plantas são ecologicamente e economicamente recomendáveis uma vez que são resíduos da agroindústria obtidos sem ônus ou a baixo custo pelos produtores.

Com base nos resultados observados nos dois experimentos, os autores concluem que a viabilidade das sementes de Brassavola tuberculata é favorecida pela diminuição de temperatura e recomendam o seu armazenamento em refrigerador $\left(4 \pm 2{ }^{\circ} \mathrm{C}\right)$ e que os substratos esfagno, fibra de coco e carvão podem ser usados na aclimatização de plantas dessa espécie.

\section{Agradecimentos}

À FUNDECT e à CAPES pela concessão de bolsa e apoio financeiro.

\section{Referências}

AGUIAR, I. B. Conservação de sementes. In: SILVA, A.; PIÑA-RODRIGUES, F. C. M.; FIGLIOLIA, M. B. Manual técnico de sementes florestais. São Paulo: Instituto Florestal, 1995. p. 33-44.

ALTAFIN, V. L.; MENEZES, M. O.; LIMA, R. R.; PITOMBO, L. M. Semeadura in vitro de orquideas para propagação massal. Espírito Santo do Pinhal: Unipinhal, 2003. 14 p. (Boletim técnico, 7).

ALVAREZ-PARDO, V.; FERREIRA, A. G. Armazenamento de sementes de orquídeas. Revista Brasileira de Sementes, Pelotas, v. 28, n. 2, p. 92-98, 2006.

ASSIS, A. M.; FARIA, R. T.; COLOMBO, L. A.; CARVALHO, J. F. R. P. Utilização de substratos à base de coco no cultivo de Dendrobium nobile Lindl. (Orchidaceae). Acta Scientiarum, Maringá, v. 27, n. 2, p. 255-260, 2005.

ASSIS, A. M.; FARIA, R. T.; UNEMOTO, L. K.; COLOMBO, L. Cultivo de Oncidium baueri Lindley (Orchidaceae) em substratos a base de coco. Ciência e Agrotecnologia, Lavras, v. 32, n. 3, p. 981-985, 2008.

BOSA, N.; CALVETE, E. O.; NIENOW, A. A.; SUZIN, M. Enraizamento e aclimatização de plantas micropropagadas de gipsofila. Horticultura Brasileira, Brasília, v. 21, n. 2, p. 207-210, 2003.

CAMPOS. D. M. Orquídeas: manual prático de reprodução. Rio de Janeiro: Expressão e Cultura, 2002. $127 \mathrm{p}$.

DRONK, A. G.; SILVA, A. P. V.; CUQUEL, F. L.; FARIA, R. T. Desenvolvimento vegetativo de híbrido de orquídea em diferentes substratos. Semina: Ciências Agrárias, Londrina, v. 33, n. 6, p. 2109-2114, 2012.

EIGELDINGER, O.; MURPHY, L. S. Cattleya. In: EIGELDINGER, O.; MURPHY, L. S. Orchids, a complete guide to cultivation. London: John Glifford LTDA, 1972. p. 154-167.

EPSTEIN, E.; BLOOM, A. J. Nutrição mineral de plantas: principios e perspectivas. 2. ed. Londrina: Planta, 2006. 403 p.

FERRAZ, M. V.; CENTURION, J. F.; BEUTLER, A. N. Caracterização física e química de alguns substratos comerciais. Acta Scientiarum Agronomy, Maringá, v. 27, n. 2, p. 209-214, 2005.

FERREIRA, D. F. Sisvar: a computer statistical analysis system. Ciência e Agrotecnologia, Lavras, v. 35, n. 6, p. 1039-1042, 2011. 
GRATTAPAGLIA, D.; MACHADO, M. A. Micropropagação. In: TORRES, A. C.; CALDAS, L. S.; BUSO, J. A. Cultura de tecidos e transformação genética de plantas. Brasília: EMBRAPA, CBAB/EMBRAPA, v. 1, 1998. p. 183-260.

GUERRINI, A.; TRIGUEIRO, R. M. Atributos físicos e químicos de substratos compostos por biossólidos e casca de arroz carbonizada. Revista Brasileira de Ciência do Solo, Viçosa, MG, v. 28, n. 6, p. 1069-1076, 2004.

HERING, M.; PUTZKE, M. T. L. Distribuição de Cattleya, Brassavola e Sophronitis (Orchidaceae) e caracterização de habitats no município de Estrela, RS, Brasil. Caderno de Pesquisa, Santa Cruz do Sul, v. 19, n. 2, p. 24-36, 2007.

HOSOMI, S. T.; CUSTÓDIO, C. C.; SEATON, P. T.; MARKS, T. R.; MACHADO-NETO, N. B. Improved assessment of viability and germination of Cattleya (Orchidaceae) seeds following storage. In vitro Cellular and Development Biology - Plant, New York, v. 48, n. 1, p. 127-136, 2012.

KÄMPF, A. N. Substratos. In: KÄMPF, A. N. Produção comercial de plantas ornamentais. Guaíba: Agropecuária, 2000. p. 45-73.

KRZYZANOWISKI, F. C.; VIEIRA, R. D.; FRANÇA NETO, J. B. Vigor de sementes: conceitos e testes. Londrina: ABRATES, 1999. 218 p.

LAUZER, D.; ST-ARNAUD, M.; BARABÉ, D. Tetrazolium staning and in vitro germination of mature seeds of Cypripedium acaule (Orchidaceae). Lindleyana, Palm Beach, v. 9, n. 3, p. 197-204, 1994.

LONE, A. B.; BARBOSA, C. M.; TAKAHASHI, L. S. A.; FARIA, R. T. Aclimatização de Cattleya (Orchidaceae) em substratos alternativos ao xaxim e ao esfagno. Acta Scientiarum Agronomy, Maringá, v. 30, n. 4, p. 465-469, 2008.

LONE, A. B.; TAKAHASHI, L. S. A.; FARIA, R. T.; ASSIS, A. M.; UNEMOTO, L. K. Desenvolvimento vegetativo de orquídeas submetidas a diferentes formulações de macronutrientes e freqüências de adubação durante a fase de aclimatização. Semina: Ciências Agrárias, Londrina, v. 31, n. 4, p. 895-900, 2010.

MACEDO, M. C.; ROSA, Y. B. C. J.; SCALON, S. P. Q.; ROSA JUNIOR, E. R.; VIEIRA, M. C.; TATARA, M. B. Substratos e intensidades luminosas no cultivo de orquídea denfal. Horticultura Brasileira, Brasília, v. 29, n. 2, p. 168-173, 2011.
MARTINS, L.; LAGO, A. A. Conservação de sementes de Cedrela fissilis: teor de água da semente e temperatura do ambiente. Revista Brasileira de Sementes, Londrina, v. 30, n. 1, p. 161-167, 2008.

MATTIUZ, C. F. M.; RODRIGUES, T. J. D.; MATTIUZ, B. Aspectos fisiológicos de orquídeas cortadas. Revista Brasileira de Horticultura Ornamental, Campinas, v. 12, n. 1, p. 21-30, 2006.

MELLO, C. M. C. Conservação de sementes de orquídeas do cerrado. 2000. Dissertação (Mestrado em Biologia) Universidade de Brasília, Brasília.

MORAES, L. M.; CAVALCANTE, L. C. D.; FARIA, R. T. Substratos para aclimatização de plântulas de Dendrobium nobile Lindl. (Orchidaceae) propagadas in vitro. Acta Scientiarum Agronomy, Maringá, v. 24, n. 5, p. 1397-1400, 2002.

MUGAMBI, G.; WOOD, C. Research on kenyan orchid seeds. Samara: The International Newsletter of the Partners of the Millennium Seed Bank Project, 2002. n. $2,17 \mathrm{p}$

MULLER, T. S.; DEWES, D.; KARSTEN, J.; SCHULTER, A. R.; STEFANELLO, S. Crescimento in vitro e aclimatação de plântulas de Miltonia flavescens. Revista Brasileira de Biociências, Porto Alegre, v. 5, p. 252-254, 2007. Suplemento 2.

MWEETWA, A. M.; WELBAUM, G. E.; TAY, D. Orchid seed storage for germplasm preservation. Acta Horticulturae, Seoul, v. 760, p. 629-635, 2007. Disponível: $\quad<\mathrm{http}: / /$ www.ishs.org/ishs-book/760> Acesso em: 30 mar. 2014.

PARDO, V. A.; FERREIRA, A. G. Armazenamento de sementes de orquídeas. Revista Brasileira de Sementes, Pelotas, v. 28, n. 1, p. 92-98, 2006.

RECH, A. R.; ROSA, Y. B. C. J.; MANENTEBALESTIERE, F. C. L. Aspects of the reproductive biology of Brassavola cebolleta Rchb.f. (Orchidaceae). Acta Scientiarum Biological Sciences, Maringá, v. 32, n. 4, p. 335-341, 2010.

SEATON, P. T.; PRITCHARD, H. W. Orchid seed stores for sustainable use: a model for future seed-banking activities. Lankesteriana, Cartago, v. 11, n. 3, p. 349353, 2011. Disponível: <http://www.lankesteriana.org/ lankesteriana/LANKESTERIANA\%2011(3)\%20/21 Lankesteriana\%2011(3)\%20Seaton\&Pritchard.pdf $>$. Acesso em: 18 fev. 2013.

SOARES, J. S.; ROSA, Y. B. C. J.; MACEDO, M. C.; SORGATO, J. C.; ROSA, D. B. C. J. R.; ROSA, C. B. C. J. Cultivo in vitro de Brassavola tuberculata (Orchidaceae) em meio de cultura alternativo suplementado com diferentes concentrações de açúcar e carvão ativado. Magistra, Cruz das Almas, v. 24, n. 3, p. 226-233, 2012a. 
SOARES, J. S.; ROSA, Y. B. C. J.; SUZUKI, R. M.; SCALON, S. P. Q. S.; ROSA JUNIOR, E. J. Germinação assimbiótica e desenvolvimento de Dendrobium nobile Lindl. sob efeito de reguladores vegetais no tratamento pré-germinativo. Revista Brasileira de Plantas Medicinais, Botucatu, v. 14, n. 4, p. 617-623, 2012 b.

SOARES, J. S.; ROSA, Y. B. C. J.; SUZUKI, R. M.; SCALON, S. P. Q. S.; ROSA JUNIOR, E. J. Cultivo in vitro de Dendrobium nobile com uso de água de coco no meio de cultura. Horticultura Brasileira, Brasília, v. 31, n. 1, p. 63-67, 2013.

SOUZA, M. Muito além do xaxim. Natureza, São Paulo, v. 1, n. 2, p. 32-37, 2003.

TAKANE, R. J.; FARIA, R. T.; ALTAFIN, V. L. Tecnologia fácil - 75: cultivo de orquídeas. Brasília: LK. 2006. $131 \mathrm{p}$.
VIEIRA, A. H.; MARTINS, E. P.; PEQUENO, P. L. L.; LOCATELLI, M.; SOUZA, M. G. Técnicas de produção de sementes florestais. Porto Velho: EMBRAPA, CT 205, 2001.4 p.

VIEIRA, R. D.; CARVALHO, N. M. Testes de vigor de sementes. Jaboticabal: FUNEP, 1994. 164 p.

YAMAKAMI, J. K.; FARIA, R. T.; STENZEL, N. M. C. Desenvolvimento vegetativo de Brassocattleya pastoral 'Rosa' e Miltonia regnelli Rchb.f. $x$ Oncidium crispum L. (Orchidaceae) em substratos alternativos à fibra de xaxim. Cientifica, Jaboticabal, v. 37, n. 1, p. 32-38, 2009.

ZANETTI, M.; CAZETTA, J. O.; MATTOS JÚNIOR, D.; CARVALHO, S. A. Uso de subprodutos de carvão vegetal na formação do porta-enxerto limoeiro 'Cravo' em ambiente protegido. Revista Brasileira de Fruticultura, Jaboticabal, v. 25, n. 3, p. 508-512, 2003. 